\title{
Molecular characterisation of enteroviruses and clinical findings from a cluster of paediatric viral meningitis cases in Tshwane, South Africa 2010-2011
}

Marianne Wolfaardt ${ }^{\mathrm{a}, 1}$, Ané Büchner ${ }^{\mathrm{b}, 1}$, Marcelle Myburgh ${ }^{\mathrm{a}, \mathrm{c}, 2}$, Theunis Avenant ${ }^{\mathrm{b}}$, Nicolette $\mathrm{M}$ du Plessis $^{\mathrm{b}}$, Maureen B Taylor ${ }^{\mathrm{a}^{*}}$

${ }^{a}$ Department of Medical Virology, Faculty of Health Sciences, University of Pretoria, Private Bag X323, Arcadia 0007 South Africa.

${ }^{b}$ Department of Paediatrics, Kalafong Academic Hospital and Faculty of Health Sciences, University of Pretoria, Private Bag X396, Pretoria 0001, South Africa

'Department of Medical Virology, National Health Laboratory Service Tshwane Academic Division, Private Bag X323, Arcadia 0007, South Africa.

${ }^{1}$ M.W. and A.B. contributed equally to this manuscript
${ }^{2}$ Current address: Molecular Biology Laboratory, AMPATH, Private Bag X9, Highveld Park 0067, South Africa

M Wolfaardt: marianne.wolfaardt@up.ac.za

A Büchner: Ane.Buchner@up.ac.za

M Myburgh: myburghm@ampath.co.za

T Avenant: theunis.avenant@up.ac.za

NM Du Plessis: nicolette.duplessis@up.ac.za

MB Taylor: maureen.taylor@up.ac.za

*Correspondence

Professor Maureen B Taylor

Department of Medical Virology, Faculty of Health Sciences, University of Pretoria

Private Bag X323, Arcadia, 0007, South Africa 
E-mail: maureen.taylor@up.ac.za

Telephone: (+2712) 3192358

Fax: (+2712) 3255550

\section{GRAPHICAL ABSTRACT}

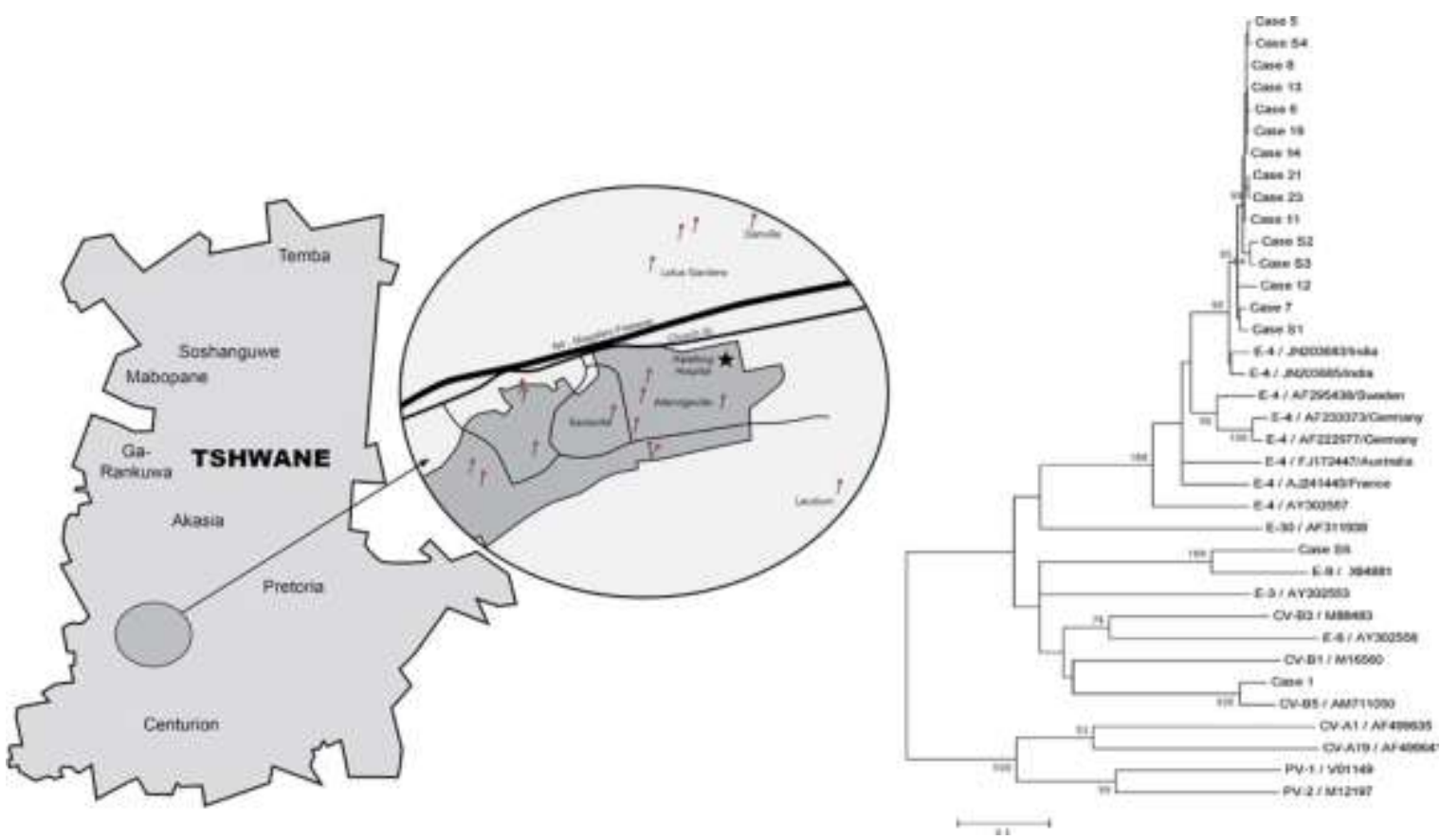

ABSTRACT

Background: Human enteroviruses (HEVs) are the most common viral pathogen associated with paediatric aseptic meningitis. From October 2010 - February 2011 a cluster of EV-associated meningitis cases was identified in paediatric patients who had presented at two large tertiary hospitals in Pretoria in the Tshwane Metropolitan Area, Gauteng, South Africa (SA).

Objectives: The aim of this study was to review the clinical features and to characterise the HEV strains associated with this cluster of meningitis cases. 
Study design: In this retrospective study HEVs, detected by real time reverse transcriptionpolymerase chain reaction in acute phase cerebrospinal fluid specimens from 30 patients with aseptic meningitis, were characterised and the clinical presentations of these patients were described.

Results: Fever (83\%), headache (70\%) and vomiting (67\%) were the most prominent symptoms with signs of meningeal irritation recorded in $67 \%$ of the patients. There was a neutrophil predominance in the cerebrospinal fluid of $57 \%$ of the patients with pleocytosis. Based on partial nucleotide sequence analysis of the HEV viral protein 1 gene, echovirus (E) serotype 4 (E-4) was identified in $80 \%(24 / 30)$ of specimens with E-9 (3/30), E-3 (1/30), coxsackie virus (CV)-B4 (1/30) and CV-B5 $(1 / 30)$ detected less frequently.

Conclusion: In this cluster of aseptic meningitis cases E-4 was the predominant strain with E-9, and to a lesser extent other HEVs, identified less frequently.

Key words: Aseptic meningitis, echovirus type 4, cerebrospinal fluid, real-time RT-PCR, South Africa

\section{Background}

Human enteroviruses (HEVs) are the most common cause of aseptic meningitis in both children and adults and are responsible for $85 \%$ - 95\% of all cases with an identifiable pathogen $[1,2]$. Human enteroviruses are single-stranded RNA viruses belonging to the genus Enterovirus, family Picornaviridae and are classified into four species (HEV-A to HEV-D)[3]. Although most HEV infections are subclinical or cause only mild undifferentiated febrile illness [4], HEVs are neurotropic, causing different clinical syndromes including acute flaccid paralysis, encephalitis and meningitis [5]. Certain HEVs, namely coxsackievirus B5 (CV-B5), echovirus serotypes 6, 9 and 30 (E-6, E-9, E-30) are more likely to cause meningitis outbreaks, while others, namely coxsackieviruses A9 (CV-A9) and CV-B3, CV-B4), are associated with endemic infection [2]. The clinical manifestation and 
severity of HEV meningitis varies with the host's immune status and age $[1,6]$, with neonates at risk for severe illness [6].

The causal association between HEV infection and disease is inferred by the detection or isolation of the virus from the site of clinical symptoms which is usually sterile, e.g. cerebrospinal fluid (CSF). The laboratory diagnosis of HEVs is dependent on labour-intensive virus isolation and identification in cell culture or more sensitive and rapid molecular-based direct detection methods such as the reverse transcriptase-polymerase chain reaction (RT-PCR)[7, 8]. Various RT-PCR formats are available and assays targeting the $5^{\prime}$ non-translated region (NTR) of the HEV genome, which is the most conserved genomic region among EVs, are essential for diagnostic use $[7,9,10]$. Typing of HEVs during outbreak investigations is important as HEVs can be associated with specific disease manifestations $[7,9]$. Molecular typing systems, which can be applied to isolates found to be difficult to type or untypable by neutralisation assays, usually target the VP1 region of the HEV genome which encodes serotype-specific neutralisation epitopes [7, 11, 12].

From October 2010 to February 2011 a marked increase in the number of cases of aseptic meningitis was seen in paediatric patients presenting at two large tertiary hospitals in Pretoria, a city in the Tshwane Metropolitan Area, Gauteng, South Africa (SA). Human enteroviruses were detected, by qualitative real-time RT-PCR, in acute phase CSF samples from these patients.

\section{Objectives}

The objective of this study was to characterise the HEVs in the CSF specimens from these meningitis cases and to describe the clinical presentation of the patients. 


\section{Study design}

\subsection{Specimens, clinical cases and demographic data}

Cerebrospinal fluid specimens from paediatric patients, who had had clinical features suggestive of meningitis as well as HEV detection by qualitative real-time RT-PCR in a CSF specimen, and who had presented at two large tertiary hospitals in Pretoria, Gauteng, SA, namely the Steve Biko (SBAH; $n=6$ ) and Kalafong Academic Hospitals (KAH: n=24) during the period October 2010 - February 2011, were included in the study. To maintain patient confidentiality a unique case number was assigned to each patient. A review of the patient files was performed and demographic, clinical and laboratory data were collected. Home addresses were plotted on a map to establish geographical proximity.

\subsection{Molecular characterisation and phylogenetic analysis of enteroviruses}

RNA was extracted from $200 \mu \mathrm{I}$ CSF using the QIAmp viral RNA mini Kit (Qiagen, Santa Clarita, CA). The RNA was eluted in $50 \mu$ l elution buffer and screened for HEV RNA using a broadly-reactive realtime RT-PCR assay that targets the 5'-NTR of HEV genomes [13]. For typing purposes, a conventional RT-PCR was used to amplify an approximately $350 \mathrm{bp}$ region of the VP1 gene [12]. The CDNA was synthesized in a $20 \mu \mathrm{l}$ RT reaction using $10 \mu \mathrm{l}$ of template RNA, $0.5 \mathrm{mM}$ dNTPs, $50 \mathrm{U}$ RevertAid $^{\mathrm{TM}}$ Premium Reverse Transcriptase (Thermo Scientific, Waltham, MA), $20 \mathrm{U}$ of RNase inhibitor (Thermo Scientific) and 600 pmol random hexamer primers (Roche Diagnostics $\mathrm{GmbH}$, Mannheim, Germany). The reaction was performed at $25^{\circ} \mathrm{C}$ for $10 \mathrm{~min}, 50^{\circ} \mathrm{C}$ for $60 \mathrm{~min}$ followed by $85^{\circ} \mathrm{C}$ for $5 \mathrm{~min}$. Amplification was carried out in a $50 \mu \mathrm{l}$ reaction using $5 \mu \mathrm{l}$ of cDNA and 10 pmol each of primers 292 and 222 [12]. Amplicons were purified using Zymo Spin Columns (Zymo Research, Irvine, CA) and sequenced using the Big Dye Terminator Cycle Sequencing Kit v 1.3 (Applied Biosystems, Foster City, CA).

Basic sequence manipulation, verification and alignment was performed using Sequencher 4.7. Multiple sequence alignments were generated using ClustalW [14] and edited using BioEdit version 


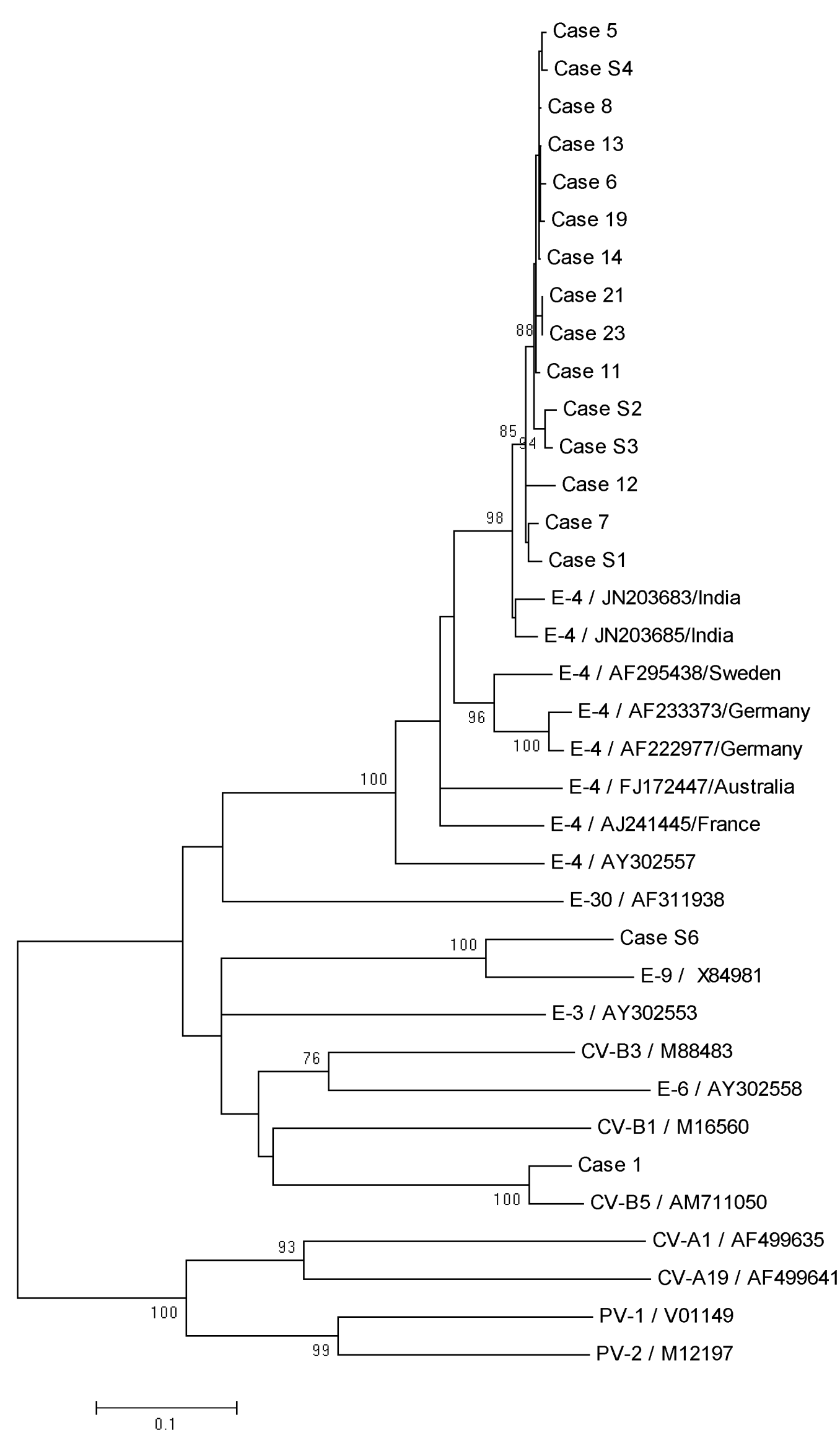

Figure 1. Neighbour-joining phylogenetic tree of the South African echovirus type 4, coxsackievirus B5 and echovirus type 9 strains in relation to selected other enterovirus nucleotide sequences In GenBank. GenBank numbers are indicated in the tree. Bootstrap values $>70 \%$, inferred from 1000 replicates, supporting each cluster are indicated. The scale bar indicates nucleotide changes per site. 
7.0.9.0 (6/27/07)[15]. A GenBank identity search using Basic Local Alignment Search Tool

(BLAST)(http://blast.ncbi.nlm.nih.gov) was performed for genotype identification as well as identification of the closest related strains. Phylogenetic relationships were inferred from the aligned nucleic acid sequences by the neighbour-joining method implemented in MEGA software version 4 [16] using the Kimura two-parameter substitution model. Included in the analysis were closely related strains of the same serotype (E-4: JN203685, AF295438, AF233373, FJ172337 and AJ241445) and strains from different serotypes (E-30: AF311938, E-9: X84981, CV-B1: AM711050 and poliovirus serotype 1: V01149). Echovirus type 4 strains with $\geq 99.5$ nucleotide sequence identity are represented by a single strain and GenBank accession numbers of reference strains used for sequence comparisons are indicated on the phylogenetic tree (Figure 1).

\section{Results}

\subsection{Molecular characterisation of enteroviruses}

The conventional RT-PCR and sequencing of the $5^{\prime}$ NTR confirmed the presence of HEVs in 30 CSF specimens. Based on phylogenetic analysis of a $350 \mathrm{bp}$ region of the VP1 genome three HEV genotypes were identified, namely E-4 (24 strains), E-9 (3 strains) and CV-B5 (1 strain)(Table 1; Figure 1). Two HEV strains (Cases 27 and S5) were not typed (Table 1). The E-4 strains resorted in a single cluster (Figure 1) and demonstrated $80.9-83.3 \%$ nucleotide sequence and $89.9-91.8 \%$ amino acid sequence identity to the prototype strain (AY302557), thus fulfilling the minimum $75 \%$ nucleotide sequence similarity criterion for genotypic identification of the serotype [11]. The genetic relationship of the South African E-4 strains to E-4 strains from other geographic regions, namely India, Sweden, Germany, Australia, France and the prototype strain from the United States of America is presented in Figure 1. The South African strains clustered, with significant bootstrap support, with E-4 strains detected in India in 2007-2009 and were distinct from the strains detected in Sweden, Germany, Australia and France. 


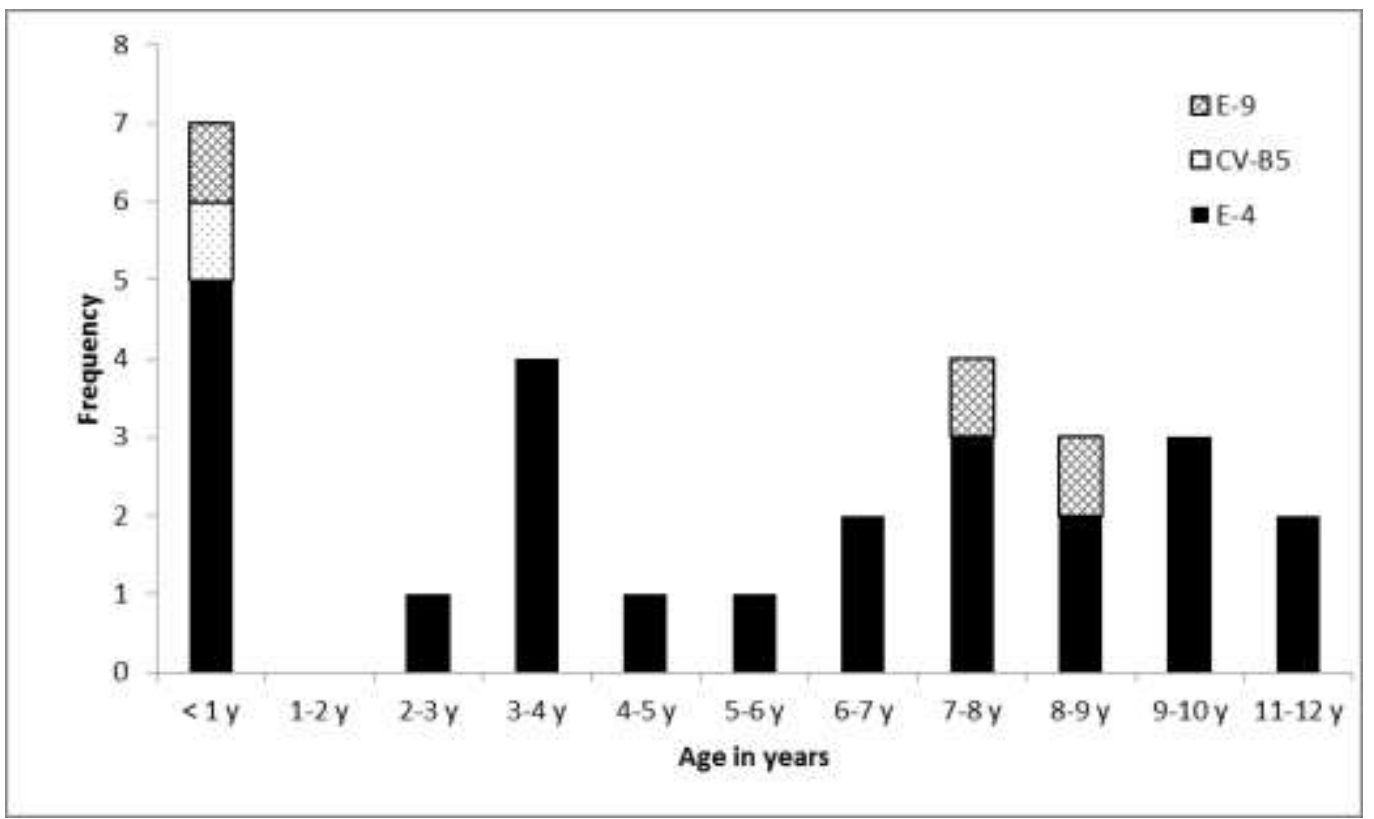

Figure 2: The patient age distribution in years indicating enterovirus types detected in each age group.

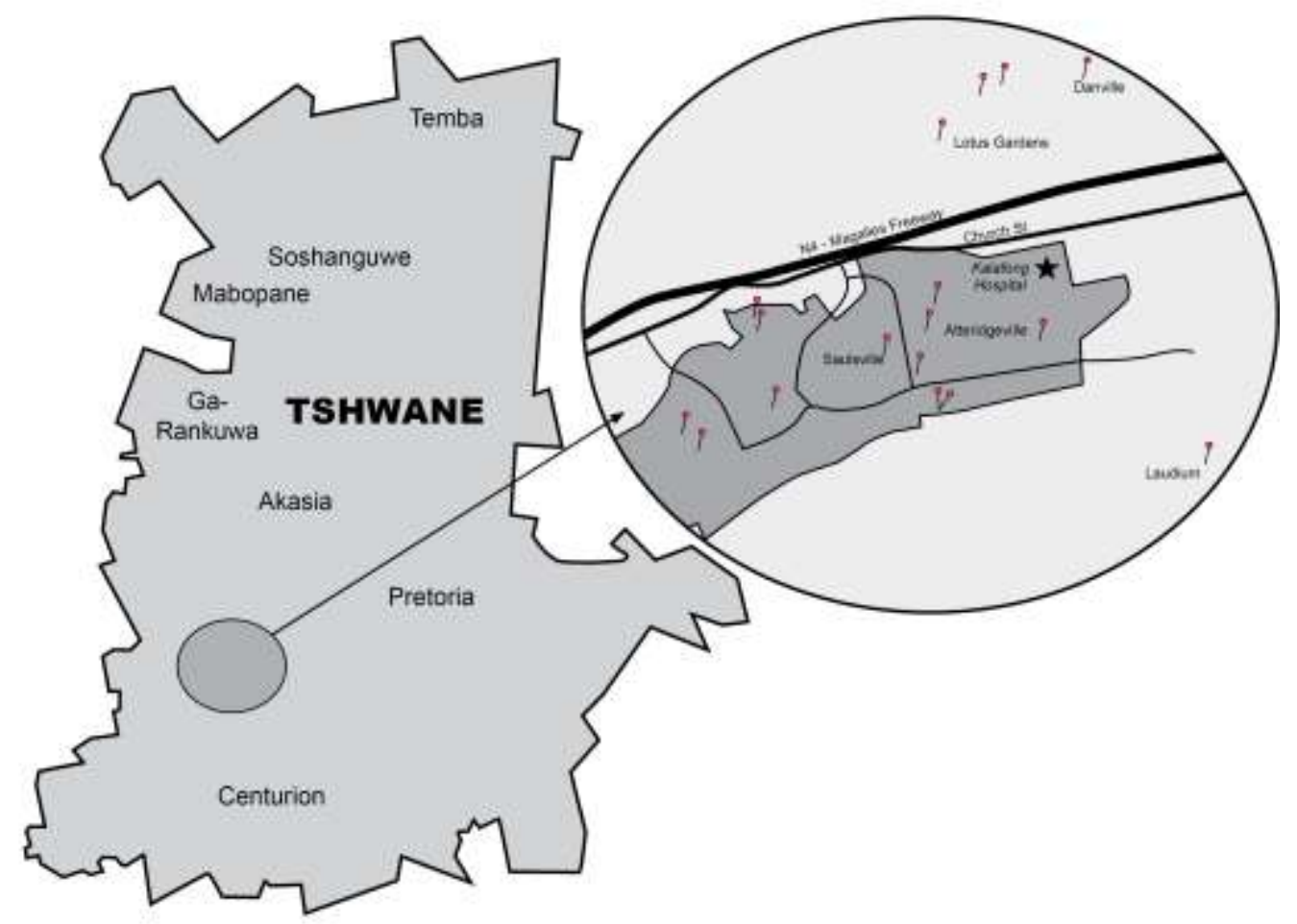

Figure 3: Diagrammatic map of the Tshwane Metropolitan Area. The insert demonstrates the geographical proximity of the patients' homes in relation to each other and to the Kalafong Academic Hospital 


\subsection{Demographic data}

Thirty-three patients were identified as having HEV-positive meningitis by routine diagnostic realtime RT-PCR analysis of CSF specimens. Specimens from thirty patients were available for further investigations. There were equal numbers of male (15) and female (15) patients with a median age of 60 months (range 1 month to 127 months [10.7 years]). Eight patients, five of whom were E-4 positive, were infants younger than one year of age (Figure2). The majority $(17 / 24 ; 71 \%)$ from whom E-4 was identified by molecular characterisation resided in an $8.4 \mathrm{~km}$ by $5.3 \mathrm{~km}$ area within the Saulsville and Atteridgeville communities in the Tshwane Metropolitan area (Figure 3). None of the patients had a significant travel history.

\subsection{Clinical data}

The most prominent clinical symptoms were fever (25/30; $83 \%)$, headache $(21 / 30 ; 70 \%)$ and vomiting $(19 / 30 ; 67 \%)($ Table 1$)$. Signs of meningeal irritation were recorded in $67 \%(20 / 30)$ and convulsions in only two of the patients. In the infant group, $88 \%(7 / 8)$ had a history of fever, $50 \%$ (4/8) presented with irritability and in 63\% (5/8) vomiting was reported. During hospitalisation, twenty-two patients (73\%) had documented fever. On clinical examination of patients older than 1 year of age, $82 \%(18 / 22)$ had meningism. In the infant group $25 \%(2 / 8)$ had a bulging fontanelle. Empiric antibiotic therapy was given to $80 \%(26 / 30)$ of the patients and $37 \%(11 / 30)$ received antiviral therapy (acyclovir), pending the results of bacterial culture and viral analysis. Therapy was discontinued upon HEV detection. The median duration of hospitalisation was 5 days (1-8 days). All patients were discharged home with no sequelae reported.

\subsection{Laboratory investigations}

Cerebrospinal fluid and peripheral white blood cell (WBC) count results were available for 29/30 and $27 / 30$ patients, respectively (Table 1 ). The median peripheral WBC count was $10.97 \times 10^{12} / \mathrm{ml}$. Microscopy revealed a pleocytosis in $71 \%(20 / 28)$ of the samples, with CSF pleocytosis defined as a 
CSF white blood cell count of $>7 / \mathrm{mm}^{3}$ [17]. There was a neutrophil predominance in $60 \%(12 / 20)$ of the patients with pleocytosis and five patients had a total leukocyte count of $>260$ cells $/ \mathrm{mm}^{3}$ (Cases $2,7,20,25,26)$. The CSF glucose and protein levels were normal in all patients except one with a traumatic tap (Case 6). Six of 28 patients (21\%) (Cases 6, 13, 18, 23, S5 and S6) did not have CSF pleocytosis, but did have clinical signs of meningitis and a positive HEV on RT-PCR. Neither herpes simplex type 1 nor any bacterial pathogens were identified as part of routine investigation of the CSF specimens. Half (15/30) of the patients' human immunodeficiency virus (HIV) status was recorded. One patient was exposed but uninfected. The other 14 patients were HIV negative and no underlying diseases were identified.

\section{Discussion}

Echoviruses were the predominant HEV identified with E-4 accounting for $80 \%(24 / 30)$ and E-9 for $10 \%(3 / 30)$ of theHEV strains. A single strain of CV-B5 was detected while two strains could not be typed. The predominance of echoviruses in this study was not an unusual finding as in recent years echoviruses have been implicated in numerous outbreaks of aseptic meningitis worldwide [18-25], including SA [10], with E-30, and to a lesser extent E-6 and E-9, being the most frequent EV serotypes identified in outbreaks, including Brazil [20], France [22], Greece [26], India [19], Italy [27, 28], Kuwait [23] and Panama [25], and E-4 considered to be a "rare" serotype [21]. The occurrence of E-4 however appears to be a localized rather than global phenomenon as E-4 has been identified as the predominant serotype in outbreaks of aseptic meningitis in Australia [24], Argentina [29], India [19], Italy [27], and in a travel-associated outbreak imported from India to Italy [28]. Echovirus type 4 has previously been associated with aseptic meningitis in SA as E-4 was responsible for epidemics of acute aseptic meningitis in closed institutions in Johannesburg and Worcester, respectively [30,31], and in an outbreak of aseptic meningitis in Cape Town in 1981-1982 [32]. A retrospective review of the aetiology of viral meningitis in Cape Town revealed that E-4 and E-9 were responsible for four major episodes of summer viral meningitis from 1981-1989 [33]. However as there is a paucity of 
data with regard to the epidemiology of HEVs in SA and no E-4 sequence data were available for comparative purposes, the phylogenetic relationship between the E-4 strains detected in this study to those from the Cape Town area could not be established. Interestingly the E-4 strains from this study were most closely related to E-4 strains from India [34], but no relevant travel history was reported for the patients. The age distribution of patients and seasonality of this cluster of aseptic meningitis cases correlates with findings from other studies in SA [10,33] and other temperate regions $[20,25,29,35]$. However in temperate regions outbreaks of HEV-associated meningitis can occur in other seasons, especially in closed settings, as was noted in Cape Town [31].

Previously reported outbreaks of enteroviral meningitis in children were characterised by the triad of fever, nausea and vomiting $[22,24]$ which was consistent with the findings of this study. In the infant group the findings of fever and irritability also correlated with previous studies $[24,36]$ and vomiting was a common symptom in both the infants $(5 / 8 ; 63 \%)$ and older children $(15 / 20 ; 75 \%)$. In contrast to an E-4-associated outbreak of aseptic meningitis reported in Australia where a significant number of infants presented with diarrhoea (57\%) and a rash (22\%)[24], there were no dermatological symptoms or diarrhoea in this infant group. The clinical course of all the patients was without sequelae which is not always the case as a fatal case of HEV-related leukoencephalitis in an 18-month old infant was noted in an outbreak in North-Eastern France [22].

In this study a neutrophil predominance in the CSF (57\%) was noted. This is in contrast to the mononuclear cell predominance found during the E-4-associated viral meningitis outbreak reported in Australia [24], but similar to other reports where the majority of children during an enteroviral season presented with neutrophil predominance in the CSF specimens [37]. The total leukocyte count of $>260$ cells $/ \mathrm{mm}^{3}$ in 5 of the cases, although unanticipated, can still fit in with ranges of 102362 cells $/ \mathrm{mm}^{3}$ in patients with viral meningitis [17]. From this investigation it is clear that the CSF pleocytosis should not be assessed in isolation, as it may lead the clinician to incorrectly diagnose bacterial meningitis. The correct early diagnosis of viral meningitis helps to determine prognosis, 
enhances care of the patient and reduces hospital stay [35]. In this cohort the median duration of hospitalisation was 5 days (1-8 days). This is comparable with a median of 4 days (1.9-8.5 days) in a large analysis of aseptic meningitis in children [38].

In conclusion, an accurate diagnosis of HEV-associated meningitis prevents the unnecessary use of antibiotics and/or antiviral medication, and pathogen specific infection prevention and control measures can be implemented $[35,38]$. Furthermore the characterisation of the circulating HEVs provides valuable epidemiological data which can be applied to identify and monitor outbreaks and can also be used to identify intercity [39] or intercountry spread of epidemic-related HEVs [29].

\section{Acknowledgements}

Funding: This study was partially supported by the National Research Foundation, South Africa (M.B.T., Grant specific reference number [UID 85799]). Any opinion, finding and conclusion or recommendation expressed in this material is that of the authors and the NRF does not accept liability in this regard.

Competing Interests: None declared

Ethical approval: This was a retrospective study which did not impact on patient management. The clinical and laboratory investigations were performed as day-to-day routine investigations where standard patient management protocols were followed. Permission to publish these data was obtained from the National Health Laboratory Service, Tshwane Academic Division and the Superintendents of the Steve Biko Academic and Kalafong Academic Hospitals.

\section{Conflict of interest}

None declared 


\section{References}

[1] Rotbart HA. Viral meningitis. Semin Neurol 2000;20:277-92.

[2] Lee BE, Davies HD. Aseptic meningitis. Curr Opin Infect Dis 2007;20:272-7.

[3] Knowles NJ, Hovi T, Hyypiä T, King AMQ, Lindberg AM, Pallansch MA, et al. Picornaviridae. In: King AMQ, Adams MJ, Carstens EB, Lefkowitz EJ, editors. Virus Taxonomy: Classification and Nomenclature of Viruses: Ninth Report of the International Committee on Taxonomy of Viruses. San Diego: Elsevier Inc; 2012, p. 855-80.

[4] Oberste MS, Pallansch MA. Coxsackieviruses. In: Mahy BWJ, van Regenmortel MHV, editors. Desk Encyclopedia of Human and Medical Virology. Oxford: Elsevier Ltd; 2010, p. 58-64.

[5] Rhoades RE, Tabor-Godwin JM, Tsueng G, Feuer R. Enterovirus infections of the central nervous system. Virology 2011;411:288-305.

[6] Romero JR. Enteroviruses. In: Richman DD, Whitley RJ, Hayden FG, editors. Clinical Virology, $3^{\text {rd }}$ edn. Washington DC: ASM Press; 2009, p. 1031-61.

[7] Pallansch MA, Oberste MS. Enteroviruses and Parechoviruses. In: Spechter S, Hodinka RL, Young SA, Wiedbrauk DL, editors, Clinical Virology Manual. $4^{\text {th }}$ edn. Washington DC: ASM Press; 2009, p. 249-82.

[8] Polage CR, Petti CA. Assessment of the utility of viral culture of cerebrospinal fluid. Clin Infect Dis 2006;43:1578-9.

[9] Tavakoli NP, Wang H, Nattanmai S, Dupuis M, Fusco H, Hull R. Detection and typing of enteroviruses from CSF specimens from patients diagnosed with meningitis/encephalitis. J Clin Virol 2008;43:20711.

[10] Yeats J, Smuts H, Serfontein CJ, Kannemeyer J.. Investigation into a school enterovirus outbreak using PCR detection and serotype identification based on the $5^{\prime}$ non-coding region. Epidemiol Infect 2005;133:1123-30. 
[11] Oberste MS, Maher K, Kilpatrick DR, Flemister MR, Brown BA, Pallansch MA. Typing of human enteroviruses by partial sequencing of VP1. J Clin Microbiol 1999;37:1288-9.

[12] Oberste MS, Nix WA, Maher K, Pallansch MA.. Improved molecular identification of enteroviruses by RT-PCR and amplicon sequencing. J Clin Virol 2003;26:375-7.

[13] Fuhrman JA, Liang X, Noble RT. Rapid detection of enteroviruses in small volumes of natural waters by real-time quantitative reverse transcriptase PCR. Appl Environ Microbiol 2005;71: 4523-30.

[14] Thompson JD, Higgins DG, Gibson TJ. CLUSTAL W: Improving the sensitivity of progressive multiple sequence alignment through sequence weighting, position-specific gap penalties and weight matrix choice. Nucleic Acids Res 1994;22:4673-80.

[15] Hall TA. BioEdit: a user-friendly biological sequence alignment editor and analysis program for Windows 95/98/NT. Nucleic Acids Symposium Series 1999;41:95-8.

[16] Tamura K, Dudley J, Nei M, Kumar S. MEGA4: Molecular evolutionary genetics analysis (MEGA) Software version 4.0. Mol Biol Evol 2007;24:1596-9.

[17] Bonsu BK, Harper MB. Differentiating acute bacterial meningitis from acute viral meningitis among children with cerebrospinal fluid pleocytosis: A multivariable regression model. Pediatr Infect Dis J 2004;23:511-7.

[18] Centers for Disease Control and Prevention. Outbreak of aseptic meningitis associated with multiple enterovirus serotypes-Romania, 1999. MMWR 2000;49:669-71.

[19] Sathish N, Scott JX, Shaji RV, Sridharan G, Vijayakumar TS, Raj A, et al. An outbreak of echovirus meningitis in children. Indian Pediatrics 2004;41:384-8.

[20] Dos Santos GPL, Skraba I, Oliveira D, Lima AAF, de Melo MMM, Kmetzsch Cl, et al. Enterovirus meningitis in Brazil, 1998-2003. J Med Virol 2006;78:98-104.

[21] Richter J, Koptides D, Tryfonos C, Christodoulou C. Molecular typing of enteroviruses associated with virus meningitis in Cyprus, 2000-2002. J Med Microbiol 2006; 55:1035-41. 
[22] Brunel D, Lévêque N, Jacques J, Renios F, Motte J, Andréoletti L. Clinical and virological features of an aseptic meningitis outbreak in North-Eastern France, 2005. J Clin Virol 2008; 42:225-8.

[23] Dalwai A, Ahmad S, Al-Nakib W. Echoviruses are a major cause of aseptic meningitis in infants and young children in Kuwait. Virology J 2010;7:236.

[24] Markey PG, Davis JS, Harnett GB, Williams SH, Speers DJ. Meningitis and a febrile vomiting illness caused by echovirus type 4, Northern Territory, Australia. Emerg Infect Dis 2010;16:63-7.

[25] Martinez AA, Castillo J, Sanchez MC, Zaldívar Y, Mendoza Y, Tribaldos M, et al. Molecular diagnosis of echovirus 30 as the etiological agent in an outbreak of aseptic meningitis in Panama: May - June 2008. J Infect Dev Ctries 2012;6:836-41.

[26] Mantadakis E, Pogka V, Voulgari-Kokota A, Tspuvala E, Emmanouil M, Kremastinou J, et al. Echovirus 30 outbeak associated with a high meninigitis attack rate in Thrace, Greece. Pediatr Infect Dis J 2013;32:914-6.

[27] Portolani M, Pecorari M, Pietrosemoli P, Bartoletti A, Sabbatini AM Meacci M, et al. Outbreak of aseptic meningitis by echo 4: prevalence of clinical cases among adults. New Microbiol 2001;24:11-5.

[28] Gobbi F, Calleri G, Spezia C, Lipani F, Balbiano R, De Agostini M, et al. Echovirus-4 meningitis outbreak imported from India. J Travel Med 2010;17:66-8.

[29] Grenón SL, Robledo ML, von Specht MH, Cisterna DM, Lema CL, Freire MC. Outbreak of viral meningitis caused by echovirus type 4 in Misiones province. Rev Argent Microbiol 2008;40:41-6.

[30] Malherbe $\mathrm{HH}$, Harwin R, Smith AH. An outbreak of aseptic meningitis associated with echo virus type 4. S Afr Med J 1957;31:1261-4.

[31] Wilsen AAJ, Peisach H, Howarth WH. A closed epidemic of acute aseptic meningitis caused by echo virus type 4. Part 1. Epidemiological and clinical studies. S Afr Med J 1961;35:330-3.

[32] Potter PC, Donald PR, Moodie J, Slater C, Kibel MA.. Meningitis in Cape Town children. S Afr Med J $1984 ; 66: 759-62$. 
[33] Mclntyre JP, Keen GA. Laboratory surveillance of viral meningitis by examination of cerebrospinal fluid in Cape Town, 1981-9. Epidemiol Infect 1993;111:357-71.

[34] Rao DC, Yergolkar P, Shankarappa KS. Antigenic diversity of enteroviruses associated with nonpolio acute flaccid paralysis, India, 2007-2009. Emerg Infect Dis 2012;18:1833-40.

[35] Logan SAE, MacMahon E. Viral meningitis. Brit Med J 2008;336:36-40.

[36] Rorabaugh ML, Berlin LE, Heldrich F, Roberts K, Rosenberg LA, Doran T, et al. Aseptic meningitis in infants younger than 2 years of age: Acute Illness and neurologic complications. Pediatrics 1993;92:206-11.

[37] Negrini B, Kelleher KJ, Wald ER. Cerebrospinal fluid findings in aseptic versus bacterial meningitis. Pediatrics 2000;105:316-9.

[38] Michos AG, Syriopoulou VP, Hadjichristodoulou C, Daikos GL, Lagona E, Douridas P, et al. Aseptic meningitis in children: Analysis of 506 cases. PLoS ONE 2007;2:e674.

[39] Tao Z, Sing Y, Wang H, Zhang Y, Yoshida H, Ji S, et al. Intercity spread of echovirus 6 in Shandong Province, China: Application of environmental surveillance in tracing circulating enteroviruses. Appl Environ Microbiol 2012;78:6946-53. 